\title{
Prognostic value of quantitative FDG-PET in the prediction of survival and local recurrence for patients with advanced oral cancer treated with superselective intra-arterial chemoradiotherapy
}

\author{
TOMOYUKI OYAMA ${ }^{1}$, YOICHIRO HOSOKAWA ${ }^{2}$, KAZUKI ABE ${ }^{1}$, KAZUKI HASEGAWA $^{2}$, \\ ROMAN FUKUI ${ }^{2}$, MASAHIKO AOKI ${ }^{3}$ and WATARU KOBAYASHI ${ }^{4}$ \\ ${ }^{1}$ Faculty of Graduate School of Biomedical Sciences and Engineering, Hokkaido University, Hokkaido 061-0293; \\ ${ }^{2}$ Department of Radiation Science, Graduate School of Health Sciences, \\ Hirosaki University, Aomori 036-8564; Departments of ${ }^{3}$ Radiology and Radiation Oncology, and \\ ${ }^{4}$ Oral and Maxillofacial Surgery, Graduate School of Medicine, Hirosaki University, Aomori 036-8562, Japan
}

Received August 2, 2019; Accepted January 24, 2020

DOI: $10.3892 / 01.2020 .11488$

\begin{abstract}
The current study aimed to evaluate the relationship between $18 \mathrm{~F}$-fluorodeoxyglucose positron emission tomography with computed tomography (FDG-PET-CT) standardized uptake value (SUV) [pre-treatment SUV (pre-SUV) and post-treatment SUV (post-SUV)] and treatment results in patients with advanced oral cancer treated with superselective intra-arterial chemoradiotherapy (SSIACRT). A total of 37 patients with advanced oral cancer were treated with SSIACRT. The treatment consisted of superselective intra-arterial chemotherapy (docetaxel (DOC) $40 \mathrm{mg} / \mathrm{mm}^{2}$ and nedaplatin (CDGP) $80 \mathrm{mg} / \mathrm{mm}^{2}$ ) and concurrent radiotherapy (60-70 Gy) for a period of seven weeks. Pre-SUV and post-SUV of the primary tumor were measured. Overall survival (OS) and local control (LC) rates were selected as endpoints to evaluate prognosis. The median follow-up was 40 months (range 6-112 months). The 5-year OS and LC rates were 64.5 and $85.5 \%$, respectively, and SSIACRT achieved high LC rate even in advanced oral cancers. In the log-rank test, post-SUV was a significant prognostic factor for OS and LC rates. The results of the current study demonstrated that SSIACRT is a reliable treatment with respect to survival in advanced oral cancer and post-SUV was a significant prognostic factor for OS and LC rates.
\end{abstract}

Correspondence to: Professor Yoichiro Hosokawa, Department of Radiation Science, Graduate School of Health Sciences, Hirosaki University, 66-1 Hon-cho, Hirosaki, Aomori 036-8564, Japan E-mail: hosokawa@hirosaki-u.ac.jp

Key words: 18F-Fluorodeoxyglucose positron emission tomography with computed tomography, advanced oral cancer, superselective intra-arterial chemotherapy, radiation therapy, local recurrence

\section{Introduction}

Superselective intra-arterial infusion of cisplatin with concomitant radiotherapy has been introduced to increase the treatment efficacy of superselective intra-arterial chemoradiotherapy (SSIACRT) for advanced head and neck cancer (1). It has an $80 \%$ complete response (CR) rate in advanced head and neck cancer (2). However, despite the significant CR rate, the survival rate of SSIACRT remains unsatisfactory (3). Previous studies have shown that $\mathrm{T}$ and $\mathrm{N}$ classification are prognostic factors that are correlated with overall survival (OS) and disease-free survival (DFS), and the risk of nodal disease is directly associated with more advanced T classification (4). Furthermore, most treatment failures occur at the primary tumor site, followed by regional nodal failure $(5,6)$. However, classic parameters, such as TNM classification, are not useful for prediction of responses, and the establishment of useful, effective, pretreatment risk stratification is vital $(7,8)$.

18 F-Fluorodeoxyglucose positron emission tomography with computed tomography (FDG-PET-CT) is a medical imaging technique that is based on the study of glucose metabolism in tumor cells. FDG-PET-CT in oral cancer has been evaluated by numerous studies. The maximum standardized uptake value (SUVmax), a semiquantitative measure of tumor uptake, has shown varied results in its role as a prognostic factor for head-and-neck squamous cell carcinoma (HNSCC) that is treated with definitive chemoradiotherapy (9-11).

The present study aimed to evaluate the treatment results and compare the pre-treatment SUV (pre-SUV) and post-treatment SUV (post-SUV) with OS and local control (LC) rates in patients with advanced oral cancer treated with SSIACRT.

\section{Materials and methods}

Patients. Between May 2003 and February 2018, 74 patients with advanced oral cancer were treated with SSIACRT at 
Hirosaki University Hospital, Hirosaki Japan. Of these, 55 patients underwent PET-CT, one prior to and several times after treatment at Hirosaki University Hospital. In this study, we restricted our population to patients who had both pre-SUV and post-SUV measurements. We excluded 5 patients who were diagnosed with neck recurrence only after they had been treated with SSIACRT because these patients did not have a primary tumor. We also excluded 2 patients with metallic artifacts of dental crowns because they hinder in SUV measurement.

Finally, 37 patients were analyzed in this study (Table I). The inclusion criteria were as follows: Oral squamous cell carcinoma (SCC) of the tongue and lower gum, floor of mouth, buccal mucosa, upper jaw and fauces and, Union for International Cancer Control TNM classification stage III to IV. A total of 34 patients were fresh newly diagnosed and 3 patients had local recurrence (LR) cases. Among the 3 patients, one had not only local LR but also neck recurrence.

This study was approved by the ethics committee of Hirosaki University Hospital, Hirosaki Japan, and informed consent was obtained from each participant. Patients provided oral and written consent to the collection of their data and consented to publication of the PET scan data as well as participation. We have read the Helsinki Declaration and have followed the guidelines in this study.

Treatment procedure. The extent of tumor invasion was assessed by CT, magnetic resonance imaging (MRI), and PET-CT. Primary tumors and all nodal areas were irradiated with 50 Gy in 25 fractions, 5 fractions a week, in a period of 5 weeks. An additional dose of 16 Gy by a boost irradiation in 8 fractions was applied on the primary tumors, with a total dose of $66 \mathrm{~Gy}$. All patients received concurrent intra-arterial DOC $\left(40 \mathrm{mg} / \mathrm{mm}^{2}\right)$ and CDGP $\left(80 \mathrm{mg} / \mathrm{mm}^{2}\right)$ infusion thrice every 4 weeks in the following manner (12).

Anticancer drugs were partially delivered to the regional neck area in patients with bulky nodal diseases confirmed to have multiple feeding arteries. The dose of drug for each feeder of bulky nodal diseases was determined by $\mathrm{CT}$ angiography. When the number of feeding arteries was more than 4 or the feeding artery was not identified using a microcatheter, an arterial redistribution technique was used. Unnecessary branches of the external carotid artery (ECA) were embolized with microcoils (Trufill Pushable Ceoil, Codman, Neurovascular, and Tornado Embolization Microcoil, Cook) via a microcatheter. The procedure was performed within the extent of the ECA. Drug infusion was performed in the radiology suite by interventional radiologists (12). This treatment has been approved by the appropriate ethical committees of Hirosaki University Hospital (Hirosaki, Japan).

Evaluation of response to therapy. Responses to therapy were assessed by clinical examination, CT, and MRI 4 weeks after the completion of SSIACRT. FDG-PET was performed 8 weeks after the completion of radiotherapy to avoid false positive results caused by inflammation (12).

The final treatment effect for a primary tumor and cervical lymph nodes was determined, considering inspection, palpation, and various diagnostic imaging modalities.
Table I. Patient characteristics $(\mathrm{N}=37)$.

\begin{tabular}{|c|c|c|}
\hline Characteristics & No. & $\%$ \\
\hline \multicolumn{3}{|l|}{ Follow-up times } \\
\hline Median & $40 \mathrm{M}$ & \\
\hline Range & 6-112 M & \\
\hline \multicolumn{3}{|l|}{ Age (years) } \\
\hline Median & 65 & \\
\hline Range & $26-79$ & \\
\hline \multicolumn{3}{|l|}{ Sex } \\
\hline Male & 31 & 83.8 \\
\hline Female & 6 & 16.2 \\
\hline \multicolumn{3}{|l|}{$\mathrm{T}$ classification } \\
\hline $\mathrm{T} 2$ & 7 & 18.9 \\
\hline T3 & 7 & 18.9 \\
\hline $\mathrm{T} 4$ & 22 & 59.5 \\
\hline Unknown & 1 & 2.7 \\
\hline \multicolumn{3}{|l|}{$\mathrm{N}$ classification } \\
\hline No & 9 & 24.3 \\
\hline N1 & 7 & 18.9 \\
\hline $\mathrm{N} 2$ & 19 & 51.4 \\
\hline N3 & 1 & 2.7 \\
\hline Unknown & 1 & 2.7 \\
\hline \multicolumn{3}{|l|}{ M classification } \\
\hline M0 & 31 & 83.8 \\
\hline M1 & 6 & 16.2 \\
\hline \multicolumn{3}{|l|}{ Primary Sites } \\
\hline Tongue & 10 & 27 \\
\hline Lower gum & 8 & 21.6 \\
\hline Floor of mouth & 7 & 18.9 \\
\hline Buccal mucous & 3 & 8.1 \\
\hline Upper jaw & 8 & 21.6 \\
\hline Fauces & 1 & 2.7 \\
\hline \multicolumn{3}{|l|}{ First diagnosis } \\
\hline Fresh & 34 & 91.9 \\
\hline Recurrence & 3 & 8.1 \\
\hline
\end{tabular}

M, months.

PET-CT imaging. FDG-PET-CT scans were performed using Discovery ST Elite 16 (GE Medical Systems). Up take time was 50-60 min after injection. FDG was injected intravenously at a dose of 100-300 MBq.

Data analysis of PET results. For the semiquantitative evaluation of FDG uptake in the primary tumor, region of interest (ROI) was placed on the area of highest FDG uptake on the PET images and the SUVmax of the primary tumor was automatically calculated (Fig. 1). Measurement of SUVmax was performed using Shade Quest View R software (Yokogawa Electric Corporation). In the evaluation, we preferred to use SUVmax as the evaluation index in order to minimize partial volume effects in the relatively small ROI (13). We measured the pre-treatment SUV (pre-SUV) and post-treatment SUV 
Table II. Pre-SUV and post-SUV ( $\mathrm{n}=37)$.

\begin{tabular}{lcc}
\hline Variable & Pre-SUV & Post-SUV \\
\hline Range & $4.9-43.0$ & $1.8-13.9$ \\
Mean \pm SD & $15.9^{\mathrm{a}} \pm 7.1$ & $5.1^{\mathrm{a}} \pm 2.7$ \\
Median & 15.4 & 4.1 \\
\hline
\end{tabular}

a $\mathrm{P}=2.15 \mathrm{E}-11$ (paired t-test); SD, standard deviation; SUV, standardized uptake value.

Table III. Pre-SUV and post-SUV between LC and LR.

\begin{tabular}{|c|c|c|}
\hline \multirow[b]{2}{*}{ Parameter } & LC group & LR group \\
\hline & \multicolumn{2}{|c|}{ Mean $\pm \mathrm{SD}(\mathrm{N})$} \\
\hline Pre-SUV & $15.8 \pm 7.6(\mathrm{~N}=32)$ & $15.9 \pm 3.8(\mathrm{~N}=5)$ \\
\hline Post-SUV & $4.3 \pm 1.4(\mathrm{~N}=32)$ & $6.0 \pm 2.0(\mathrm{~N}=4)$ \\
\hline
\end{tabular}

Data are presented as mean \pm standard deviation. SUV, standardized uptake value; LC, local control rate; LR, local recurrence.

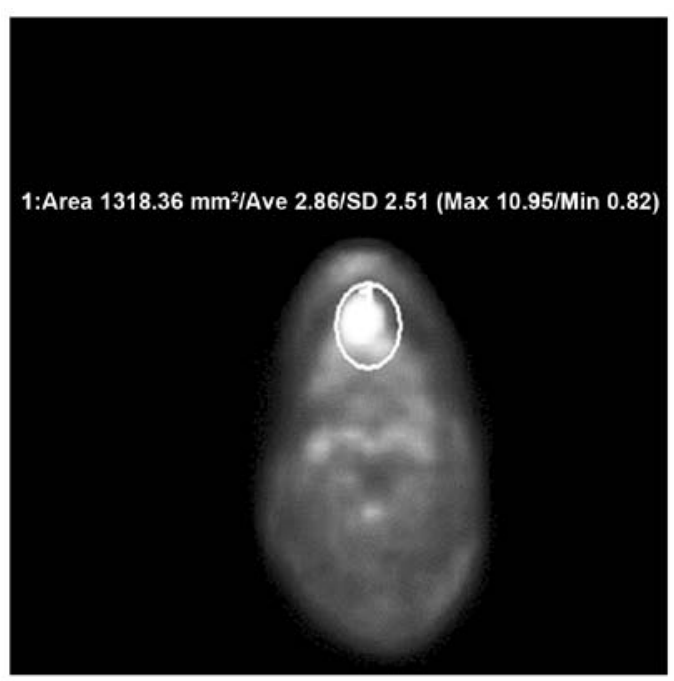

Figure 1. Measurement of primary tumor SUVmax. FDG PET image of a 61-year-old man with squamous cell carcinoma on the floor of the mouth is shown. ROI on axial image. ROI was set to include the primary tumor, and SUVmax was automatically calculated. SUV, standardized uptake value; FDG-PET-CT, Fluorodeoxyglucose positron emission tomography with computed tomography; ROI, region of interest.

(post-SUV). Finally, we compared the pre-SUV and post-SUV with OS and LC rates.

Statistical analysis. Survival curves were obtained using the Kaplan-Meier method. The significance differences of the OS, disease free (DF), and LC rates were analyzed by two-sided $\log$ rank test. SUV cut-off points were set based on the result of receiver operating characteristic (ROC) curve analysis. Paired t-test was used for the comparison of the averages between two groups of patients.

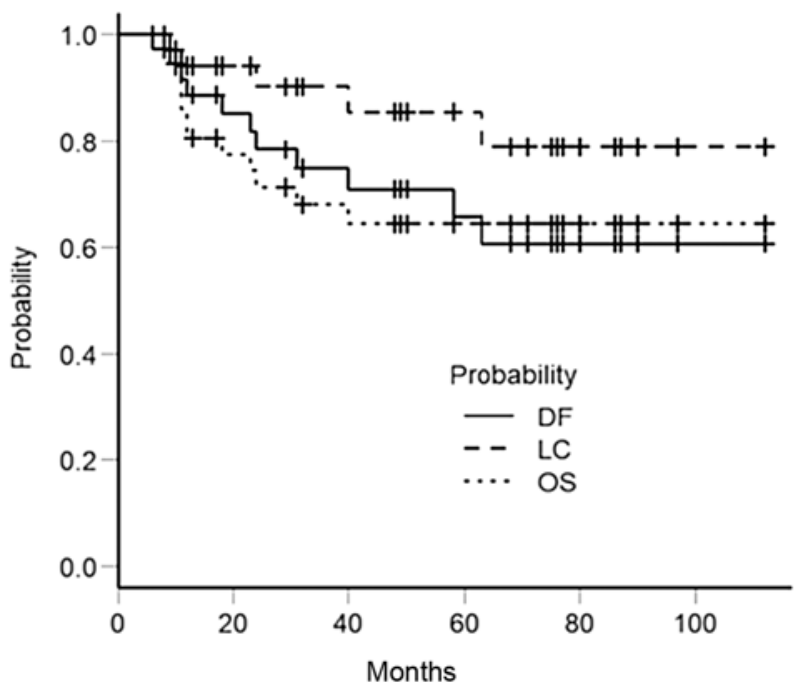

Figure 2. Treatment results of advanced oral cancer treated with superselective intra-arterial chemoradiotherapy. OS, Overall survival rate; DF, disease free rate; LC, local control rate.

Statistical significance was a defined as P-value $<0.05$. Statistical analyses were performed with EZR (Saitama Medical Center, Jichi Medical University, Saitama, Japan), which is a graphical user interface for R (The R Foundation for Statistical Computing). More precisely, it is a modified version of $\mathrm{R}$ commander designed to add statistical functions frequently used in biostatistics (14).

\section{Results}

After SSIACRT, treatment results of primary were as follows. Of the 37 patients, $32(86.5 \%)$ had CR, and 5 (13.5\%) patients had partial response (PR). Five of 37 patients $(13.5 \%)$ showed LR during follow-up. Of the 9 patients who were evaluated as PR or stable disease (SD), 5 patients received palliative treatment and 3 patients were treated surgically but unsuccessfully. One patient with residual neck disease was treated successfully by radical neck dissection. Distant metastasis (DM) was noted in 6 patients $(16.2 \%)$. Twelve patients $(32.4 \%)$ died: 5 of DM, 4 of LR, 2 of other diseases and 1 of unknown cause. The 5-year OS, DF and LC rates were 64.5\% [95\% confidence interval (CI), 45.7-78.2\%], 59.9\% (95\% CI; 40.4-74.8\%), and 85.5\% (95\% CI; 65.0-94.5\%), respectively (Fig. 2).

Fig. 3 shows the difference in OS rates between the LC and LR groups. Of 37 patients, 5 patients $(13.5 \%)$ were included in LR group and 32 patients $(86.5 \%)$ were included in LC group. Based on the Kaplan-Meier method, the 5-year OS rate in the LR group was $20.0 \%$ (95\% CI; 0.8-58.2\%) and the 5-year OS rate in LC group was $72.8 \%$ (95\% CI: 52.7-85.5\%). There was a significant difference between the 2 groups by log-rank test $(\mathrm{P}=0.0177)$.

Table II shows the date of pre-SUV and post-SUV. The range of pre-SUV and post-SUV were 4.9-43.0 and 1.8-13.9, respectively. The mean \pm standard deviation (SD) of pre-SUV and post-SUV was $15.9 \pm 7.1$ and $5.1 \pm 2.7$, respectively. The median of pre-SUV and post-SUV was 15.4 and 4.1, respectively.

Table III shows the pre-SUV and post-SUV in the LC and LR groups. A pre-SUV of 16.6 and post-SUV of 4.4 were 


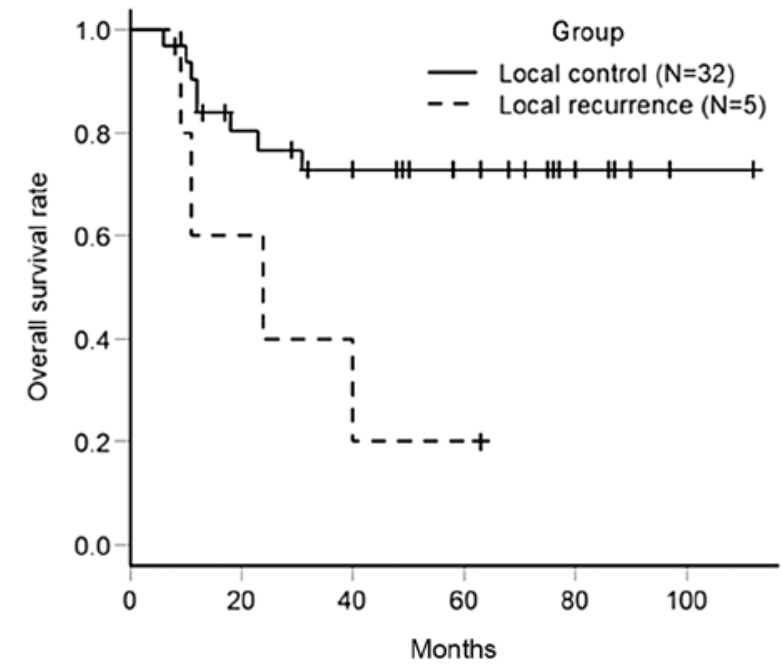

Figure 3. Comparison of OS between the LC and LR groups. Five-year OS rate in the LR group was $20.0 \%$ and that in the LC group was $72.8 \%$. There was a significant difference between the 2 groups by log-rank test $(\mathrm{P}=0.0177)$. OS, Overall survival rate; $L C$, local control rate; LR, local recurrence.
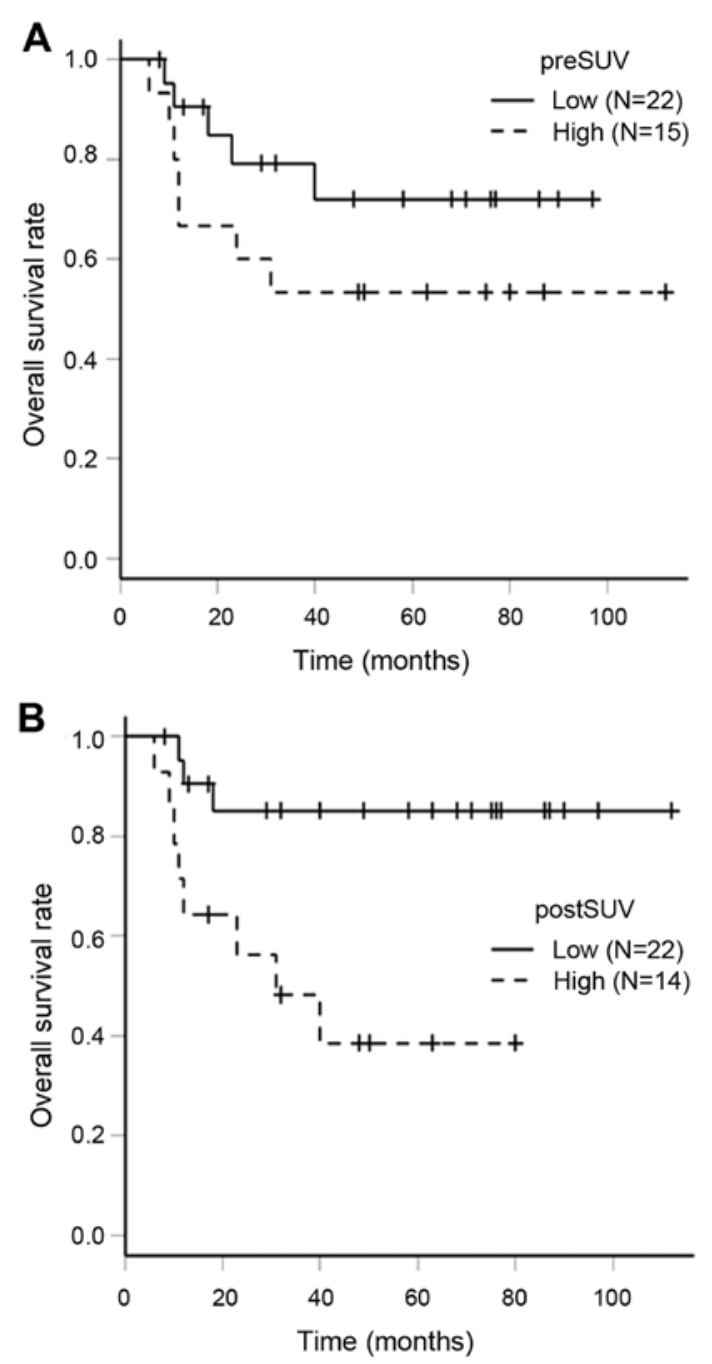

Figure 4. Comparison of OS between low SUV and high SUV groups. (A) Comparison of OS between pre-SUV $<16.6$ (low) and pre-SUV $\geq 16.6$ (high), (B) Comparison of OS between post-SUV $<4.4$ (low) and post-SUV $\geq 4.4$ (high). The comparison of OS between low and high post-SUVs indicated a significant difference $(\mathrm{P}=0.006)$. OS, Overall survival rate; SUV, standardized uptake value.
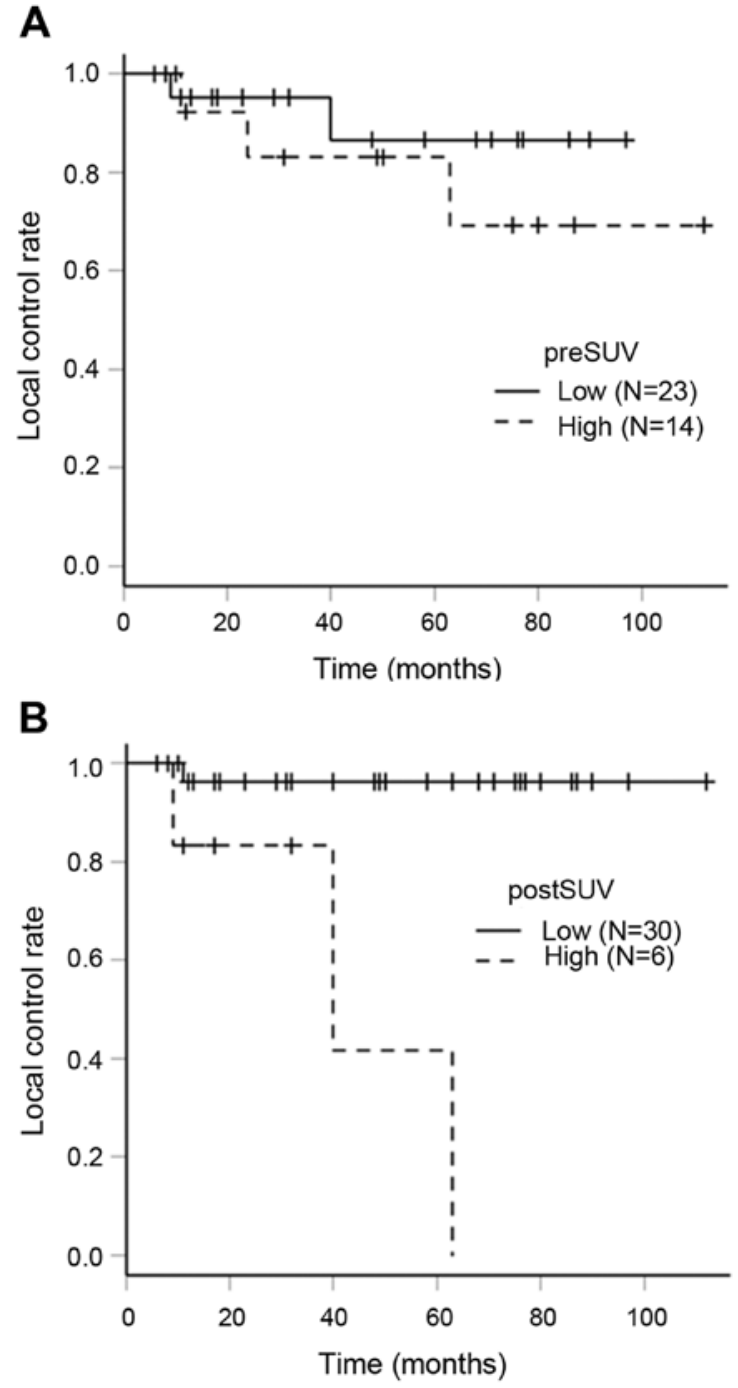

Figure 5. Comparison of LC rate between low SUV and high SUV groups. (A) Comparison of LC between pre-SUV $<16.7$ (low) and pre-SUV $\geq 16.7$ (high), (B) comparison of LC between post-SUV before LR $<6.3$ (low) and post-SUV before LR $\geq 6.3$ (high). The comparison of LC between low and high post-SUVs showed a significant difference $(\mathrm{P}=0.000187)$. LC, local control rate; SUV, standardized uptake value; LR, local recurrence.

identified as the appropriate cut-off points for ROC curve analysis. Kaplan-Meier curves of OS rates in the pre-SUV and post-SUV groups are shown in Fig. 4. A 5-year OS rate in the low pre-SUV $(<16.6)$ group and high pre-SUV $(>16.6)$ group were $75.6 \%$ (95\% CI: $46.5-90.3 \%$ ) and $50.0 \%$ (95\% CI: 24.5-71.0\%), respectively. The OS rate in the high pre-SUV group was lower than that of low pre-SUV group. However, there was no significant difference between the 2 groups by log-rank test $(\mathrm{P}=0.0726)$. The 5 -year OS rate in the low post-SUV (<4.4) group and high post-SUV (>4.4) group were $85.2 \%$ (95\% CI: 60.6-95.0\%) and 38.6\% (95\% CI: 13.4-63.6\%), respectively. There was a significant difference between the 2 groups by log-rank test $(\mathrm{P}=0.006)$.

LC rates in the pre-SUV and post-SUV groups presented in Fig. 5. The 5-year LC rate in the low pre-SUV $(<16.7)$ and high pre-SUV (>16.7) groups were 86.6\% (95\% CI: 53.9-96.7\%) and $83.1 \%$ (95\% CI: $47.2-95.5 \%$ ), respectively. There was no significant difference between the 2 groups by log-rank test $(\mathrm{P}=0.411)$. The 5-year LC rates in the low post-SUV $(<6.3)$ 
group and high post-SUV (>6.3) group were 96.3\% (95\% CI: 76.5-99.5\%) and $41.7 \%$ (95\% CI: 1.1-84.3\%), respectively. There was a significant difference between 2 groups by log-rank test $(\mathrm{P}=0.000187)$.

\section{Discussion}

This study showed treatment results and relationship between FDG-PET SUV and prognosis of patients with advanced oral cancer treated with SSIACRT. Kobayashi et al reported that the survival rate of patients with advanced oral cancer treated with SSIACRT was significantly superior to that of the surgical group (3). Furthermore, SSIACRT not only has a higher survival rate but also resulted in a better QOL compared with surgical procedures (15). Our result showed a relatively high 5-year OS rate $(64.5 \%)$ and high LC rate $(85.5 \%)$ of even advanced oral cancers. From the results of previous studies and the present study, SSIACRT is a reliable treatment modality with respect to survival in advanced oral cancer. However, DF rate (59.9\%) was low compared to the LC rate and $16.2 \%$ of patients had distant metastasis, so this problem should be considered in the future. Several studies concluded that the LC rate correlated with the OS rate (3). Our result in the comparison of OS rates between the LC and LR groups showed that the LR group had a poorer survival rate than the LC group.

Previous studies have shown that cut-off points of SUVmax of the primary tumor were set as median of SUVmax or calculated factors of DFS (16-25). In this study, SUV cut-off points for OS and LC were set based on the results of the ROC curve analysis. ROC curve analysis is used to evaluate the strength of relationships and examine the usefulness of diagnostics results (26).

In our analysis, there was a significant difference in the 5 -year OS and LC rates between the low post-SUV group and high post-SUV groups. Our results suggest that higher post-SUV is predictive of worse clinical outcomes. Minn et al reported that high FDG uptake in HNSCC is associated with poor survival (16). A similar association has also been demonstrated for other malignancies such as brain, lung, malignant lymphomas, and anus (27-30). Morikawa et al reported that pret-SUV-max was correlated with OS rate in patients with oral SCC treated with mainly surgery (26). In contrast, Suzuki et al reported that pretreatment SUV-max failed to predict the OS rate, and metabolic tumor volume using an SUV threshold of 5.0 was a significant prognostic factor for OS rate in patients with oral SCC who were treated with SSIA-CRT (31). Compared to those in their study, our result did not show that there was a significant difference in OS and LC rates between the low pre-SUV and high pre-SUV groups.

We suggest that the residual tumor cells expressed as post-SUV were critical factors in metastasis and poor prognosis, something no previous studies have shown clearly with SSLACRT. It is well known that cancer stem cells are highly resistant to radiotherapy and chemotherapy, and can contribute to recurrence and disease progression $(32,33)$. This may suggest that SSIACRT is a powerful treatment for advanced oral cancer even if the pre-SUV is high. From a point of functional organ preservation, SSIACRT should be recommended as an alternative to surgical procedures (15).
However, this study also shows that although SSIACRT is a powerful treatment method, further treatments need to be developed to completely eradicate cancer stem cells. If such a treatment is developed, even patients with high SUV will have better prognosis for advanced oral cancer.

This study has several limitations. First, our study had a retrospective design and relatively small sample size of 37 . Pre-SUV might also be selected as a statistically important factor if the analyzed sample size was larger. Second, to measure SUV of a tumor in the oral cavity, inflammation after SSIACRT and metallic artifacts of dental crowns cause inaccurate mismeasurement of SUV.

Therefore, SSIACRT achieved a high LC rate even in advanced oral cancer and a low post-SUV is statistically associated with increased OS and LC rates after SSIACRT independent of $\mathrm{T}$ and $\mathrm{N}$ classification. Our results suggest that post-SUV is an accurate predictor of prognosis and may be useful and potentially more specific in predicting LR in patients with advanced oral cancer treated with SSIACRT.

\section{Acknowledgements}

Not applicable.

\section{Funding}

No funding was received.

\section{Availability of data and materials}

The datasets used and/or analyzed during the present study are available from the corresponding author on reasonable request.

\section{Authors' contributions}

TO and KA performed statistical analysis and drafted the article. KH and RF produced figures and tables, and critically reviewed the articles. KW and MA performed patient treatment, provided patient data and provided valuable insight from their fields. YH designed the study and revised the manuscript. All authors read and approved the final manuscript.

\section{Ethics approval and consent to participate}

This study was approved by the ethics committee of Hirosaki University Hospital, Hirosaki, Japan. Patients agreed to the participation in this study and signed an informed consent form. Patients provided oral and written consent to the collection of their data and participation in the current study.

\section{Patient consent for publication}

Patients provided oral and written consent for the publication of PET scan data.

\section{Competing interests}

The authors declare that they have no competing interests. 


\section{References}

1. Robbins KT, Storniolo AM, Kerber C, Seagren S, Berson A and Howell SB: Rapid superselective high-dose cisplatin infusion for advanced head and neck malignancies. Head Neck 14: 364-371, 1992.

2. Robbins KT, Kumar P, Wong FS, Hartsell WF, Flick P, Palmer R, Weir AB III, Neill HB, Murry T, Ferguson R, et al: Targeted chemoradiation for advanced head and neck cancer: Analysis of 213 patients. Head Neck 22: 687-693, 2000.

3. Kobayashi W, Teh BG, Narita N, Ito R, Saito Y, Furudate K, Kimura H, Kakehata S and Kawaguchi H: Comparative study of superselective intra-arterial chemoradiotherapy versus radical surgery on distant metastasis for advanced oral cancer. J Oral Oncol 2014: 192734, 2014.

4. Myerson RJ, Outlaw ED, Chang A, Birnbaum EH, Fleshman JW, Grigsby PW, Kodner IJ, Malayapa RS, Mutch MG, Parikh P, et al: Radiotherapy for epidermoid carcinoma of the anus: Thirty year' experience. Int J Radiat Oncol Biol Phys 75: 428-435, 2009.

5. Das P,Bhatia S,Eng C,AjaniJA,SkibberJM,Rodriguez-Bigas MA, Chang GJ, Bhosale P, Delclos ME, Krishnan S, et al: Predictors and patterns of recurrence after definitive chemoradiation for anal cancer. Int J Radiat Oncol Biol Phys 68: 794-800, 2007.

6. Wright JL, Patil SM, Temple LK, Minsky BD, Saltz LB and Goodman KA: Squamous cell carcinoma of the anal canal Patterns and predictors of failure and implications for intensity-modulated radiation treatment planning. Int J Radiat Oncol Biol Phys 78: 1064-1072, 2010.

7. Salesiotis AN and Cullen KJ: Molecular markers predictive of response and prognosis in the patient with advanced squamous cell carcinoma of the head and neck: Evolution of a model beyond TNM staging. Curr Opin Oncol 12: 29-39, 2000.

8. Zhang Y, He W and Zhang S: Seeking for correlative genes and signaling pathways with bone metastasis from breast cancer by integrated analysis. Front Oncol 9: 138, 2019.

9. La TH, Filion EJ, Turnbull BB, Chu JN, Lee P, Nguyen K, Maxim P, Quon A, Graves EE, Loo BW Jr and Le QT: Metabolic tumor volume predicts for recurrence and death in head-and-neck cancer. Int J Radiat Oncol Biol Phys 74: 1335-1341, 2009.

10. Murphy JD, La TH, Chu K, Quon A, Fischbein NJ, Maxim PG, Graves EE, Loo BW Jr and Le QT: Postradiation metabolic tumor volume predicts outcome in head-and-neck cancer. Int $\mathrm{J}$ Radiat Oncol Biol Phys 80: 514-521, 2011.

11. Shimizu M, Mitsudo K, Koike I, Taguri M, Iwai T, Koizumi T, Oguri S, Kioi M, Hirota M, Inoue T and Tohnai I: Prognostic value of 2-[(18) F]fluoro-2-deoxy-D-glucose positron emission tomography for patients with oral squamous cell carcinoma treated with retrograde superselective intra-arterial chemotherapy and daily concurrent radiotherapy. Oral Surg Oral Med Oral Pathol Oral Radiol 121: 239-247, 2016.

12. Kobayashi W, Teh BG, Sakaki H, Sato H, Kimura H, Kakehata S and Nagahata M: Superselective intra-arterial chemoradiotherapy with docetaxel-nedaplatin for advanced oral cancer. Oral Oncol 46: 860-863, 2010.

13. Keramida G, Potts J, Bush J, Dizdarevic S and Peters AM: Hepatic steatosis is associated with increased hepatic FDG uptake. Eur J Radiol 83: 751-755, 2014.

14. Kanda Y: Investigation of the freely available easy-to-use software 'EZR' for medical statistics. Bone Marrow Transplant 48: 452-458, 2013

15. Kobayashi W, Kukobota K, Ito R, Sakaki H, Nakagawa H and Teh BG: Can superselective intra-arterial chemoradiotherapy replace surgery followed by radiation for advanced cancer of the tongue and floor of the mouth? J Oral Maxillofac Surg 74: 1248-1254, 2016.

16. Minn H, Lapela M, Klemi PJ, Grénman R, Leskinen S, Lindholm P, Bergman J, Eronen E, Haaparanta M and Joensuu H: Prediction of survival with fluorine-18-fluoro-deoxyglucose and PET in head and neck cancer. J Nucl Med 38: 1907-1911, 1997.

17. Koyasu S, Nakamoto Y, Kikuchi M, Suzuki K, Hayashida K, Itoh $\mathrm{K}$ and Togashi K: Prognostic value of pretreatment 18F-FDG PET/CT parameters including visual evaluation in patients with head and neck squamous cell carcinoma. AJR Am J Roentgenol 202: 851-858, 2014.
18. Brun E, Kjellén E, Tennvall J, Ohlsson T, Sandell A, Perfekt R, Perfekt R, Wennerberg J and Strand SE: FDG PET studies during treatment: Prediction of therapy outcome in head and neck squamous cell carcinoma. Head Neck 24: 127-135, 2002.

19. Schwartz DL, Rajendran J, Yueh B, Coltrera MD, Leblanc M, Eary $\mathbf{J}$ and Krohn K: FDG-PET prediction of head and neck squamous cell cancer outcomes. Arch Otolaryngol Head Neck Surg 130: 1361-1367, 2004.

20. Machtay M, Natwa M, Andrel J, Hyslop T, Anne PR, Lavarino J, Intenzo CM and Keane W: Pretreatment FDG-PET standardized uptake value as a prognostic factor for outcome in head and neck cancer. Head Neck 31: 195-201, 2009.

21. Halfpenny W, Hain SF, Biassoni L, Maisey MN, Sherman JA and McGurk M: FDG-PET. A possible prognostic factor in head and neck cancer. Br J Cancer 86: 512-516, 2002.

22. Torizuka T, Kanno T, Futatsubashi M, Naitou K, Ueda Y and Ouchi Y: Prognostic value of 18F-FDG PET in patients with head and neck squamous cell cancer. AJR Am J Roentgenol 192: 156-160, 2009.

23. Allal AS, Slosman DO, Kebdani T, Allaoua M, Lehmann W and Dulguerov P: Prediction of outcome in head-and-neck cancer patients using the standardized uptake value of 2-[18F] fluoro-2-deoxy-D-glucose. Int J Radiat Oncol Biol Phys 59: 1295-1300, 2004.

24. Allal AS, Dulguerov P, Allaoua M, Haenggeli CA, El-Ghazi el A, Lehmann W and Slosman DO: Standardized uptake value of 2-[(18)F] fluoro-2-deoxy-D-glucose in predicting outcome in head and neck carcinomas treated by radiotherapy with or without chemotherapy. J Clin Oncol 20: 1398-1404, 2002.

25. Roh JL, Pae KH, Choi SH, Kim JS, Lee S, Kim SB, Nam SY and Kim SY: 2-[18F]-Fluoro-2-deoxy-D-glucose positron emission tomography as guidance for primary treatment in patients with advanced-stage resectable squamous cell carcinoma of the larynx and hypopharynx. Eur J Surg Oncol 33: 790-795, 2007.

26. Morikawa T, Futoo E, Bessho H, Yakushiji T, Nomura $T$, Onodera S, Uchino Y, Takano N, Shibahara T and Katakura A: 18F-FDG PET/CT parameters as imaging biomarker is useful in oral squamous cell carcinoma patients. Jpn J Soc Oral Oncol 29: 23-35, 2017.

27. Patronas NJ, Di Chiro G, Kufta C, Bairamian D, Kornblith PL, Simon R and Larson SM: Prediction of survival in glioma patients by means of positron emission tomography. J Neurosurg 62: 816-822, 1985 .

28. Okada J, Yoshikawa K, Itami M, Imaseki K, Uno K, Itami J, Kuyama J, Mikata A and Arimizu N: Positron emission tomography using fluorine-18-fluorodeoxyglucose in malignant lymphoma: A comparison with proliferative activity. J Nucl Med 33: 325-329, 1992.

29. Ahuja V, Coleman RE, Herndon J and Patz EF Jr: The prognostic significance of fluorodeoxyglucose positron emission tomography imaging for patients with nonsmall cell lung carcinoma. Cancer 83: 918-924, 1998

30. Cardenas ML, Spencer CR, Markovina S, DeWees TA,Mazur TR Weiner AA, Parikh PJ and Olsen JR: Quantitative FDG-PET/CT predicts local recurrence and survival for squamous cell carcinoma of the anus. Adv Radiat Oncol 2: 281-287, 2017.

31. Suzuki-Shibata S, Yamamoto Y, Yoshida T, Mizoguchi N, Nonaka T, Kubota A, Narimatsu H, Miyagi Y, Kobayashi T, Kaneta T and Inoue T: Prognostic value of volumetric FDG PET/CT parameters in patients with oral tongue squamous cell carcinoma who were treated by superselective intra-arterial chemoradiotherapy. Jpn J Radiol 35: 740-747, 2017.

32. Chi HC, Tsai CY, Tsai MM, Yeh CT and Lin LH: Roles of long noncoding RNAs in recurrence and metastasis of radiotherapy-resistant cancer stem cells. Int J Mol Sci 18: pii: E1903, 2017.

33. Sen Z, Zhan XK, Jing J, Yi Z and Wanqi Z: Chemosensitizing activities of cyclotides from Clitoria ternatea in paclitaxel-resistant lung cancer cells. Oncol Lett 5: 641-644, 2013.

This work is licensed under a Creative Commons Attribution-NonCommercial-NoDerivatives 4.0 International (CC BY-NC-ND 4.0) License. 